\title{
Çölyak Arter Stenozu Olan Bir Olguda Cerrahi Tedavi: Aorta-Hepatik Bypass
}

\section{Surgical Treatment in A Patient with Celiac Artery Stenosis: Aorta-Hepatic Bypass}

Mehmet Işık ${ }^{1}$,

Ali Sarıgül ${ }^{2}$,

${ }^{1}$ Necmettin Erbakan Üniversitesi, Meram Tıp Fakültesi, Kalp ve Damar Cerrahisi Anabilim Dalı Konya, Türkiye.

${ }^{2}$ Karatay Üniversitesi, Tıp Fakültesi, Kalp ve Damar Cerrahisi Anabilim Dalı, Konya, Türkiye

Geliş Tarihi/Received: 1 Mart 2019

Kabul Tarihi/Accepted: 20 Eylül 2019

Yazışma Adresi: Mehmet Işık, Necmettin Erbakan Üniversitesi, Meram Tıp Fakültesi, Kalp ve Damar Cerrahisi Anabilim Dalı, Konya, Türkiye

e-posta:drmisik@hotmail.com

ORCID

Mehmet Işık

https://orcid.org/0000-0002-2154-7473

Ali Sarıgül

https://orcid.org/0000-0002-6338-3227

\begin{abstract}
Öz
Kronik mezenterik iskemi, çeşitli nedenlerle gastrointestinal sistemin kanlanmasında azalmaya bağlı meydana gelen nadir bir hastalıktır. Şikâyetler, özellikle yemeklerden sonra ortaya çıkar. Karın ağrısı, iştahsızlık, kilo kaybı gibi belirtilerle seyreder. Olgu sunumu yapılan hastada, intestinal iskemi, arterya dorsalis pedis tıkanıklığı, çölyak arter (ÇA) ve süperior mezenterik arter (SMA) tutulumu mevcuttu. 35 yaşındaki bayan hastada tüm bu lezyonların birlikte görülmesi, nadir olması açısından ilginçti. Bu çalışmada, endovasküler işleme uygun olmayan ve safen ven ile aorta-hepatik bypass yapılan genç
\end{abstract} hastanın cerrahi tedavisi paylaşılmak istendi.

Anahtar Kelimeler: Mezenterik iskemi, çölyak arter, safen ven, endovasküler prosedür

\section{Abstract}

Chronic mesenteric ischemia is a rare disease caused by a decrease in blood flow to the gastrointestina tract. Complaints occur especially after meals. He has symptoms such as abdominal pain, loss of appetite and weight loss. The patient was presented with intestinal ischemia, arterial dorsalis pedis obstruction celiac artery and superior mesenteric artery involvement. The coexistence of all these lesions in a 35-yearold female patient was interesting because of its rarity. In this study, we wanted to share the surgical treatment of a young patient who was not suitable for endovascular treatment and underwent saphenous vein and aorta-hepatic bypass due to multiple lesions.

Keywords: Mesenteric ischemia, celiac artery, saphenous vein, endovascular procedure

\section{GíRiş}

Kronik karın ağrısına neden olan birçok hastalık bilinmektedir. Özellikle kadınlarda karın ağrısının etiyolojisini ayırt etmek oldukça zordur. İskemiye bağlı karın ağrısı vakaları az görüldüğü için tanı aşamasında en son akla gelmektedir.

İzole ÇA stenozunun en önemli nedenleri aterosikleroz ve ÇA sıkışma sendromudur. Asemptomatik bireylerde izole çölyak arter stenozunun görülme sıklığının $\% 2,3$ ile $\% \quad 7,2$ arasında olduğu bildirilmiştir (1). Abdominal anjina kilo kaybı, anoreksi ve postprandiyal karın ağrısı olarak 20. yüzyıl başlarında tanımlanmıştır (2). Abdominal anjina, gastrointestinal sisteme giden kanın herhangi bir nedenle azalmasına bağlı olarak, bu bölgedeki organların yetersiz beslenmesi ile ortaya

Atıf yapmak için: Işık M, Sarıgül A. Çölyak Arter Stenozu Olan Bir Olguda Cerrahi Tedavi: Aorta-Hepatik Bypass. Selcuk Med J 2020;36(2): 147-150 çıkar. Intestinal anjinaya yol açan bir başka durumda median arcuat ligamanın düşük seviyeli yerleşmesi sonucu ÇA'yı diyaframın altında sıkıştırması ile oluşan ÇA bası sendromudur.

Tanı doppler ultrasonografi, CT anjiografi ve MR anjiografi ile konulur. Endovasküler işlemler hasta konforu nedeniyle öncelikli tedavi yöntemi iken, bu işlemlere uygun olmayan hastalarda cerrahi tedavi alternatiftir. Tanı ve tedavide geç kalınması durumunda, bağırsak infarktüsünden yaşam kaybına kadar giden sonuçlarla karşılaşılabilir.

OLGU

35 yaşında bayan hasta. 2 aydır iştahsızlık, yemeklerden sonra meydana gelen karın ağrısı ve isal şikâyetleri mevcuttu. 20 yıldır günde 2 paket

Açıklama: Yazarların hiçbiri, bu makalede bahsedilen herhangi bir ürün, aygut veya ilas ile ilgili maddi cıkar iliskisine sahip değildir. Arastırma herhangi bir dıs organizasyon tarafından desteklenmedi Yazarlar calısmanin thirit verilerine birincil verilerine tam erişim izni vermek ve derginin talep ettiği takdirde verileri incelemesine izin vermeyi kabul etmektedirler. 


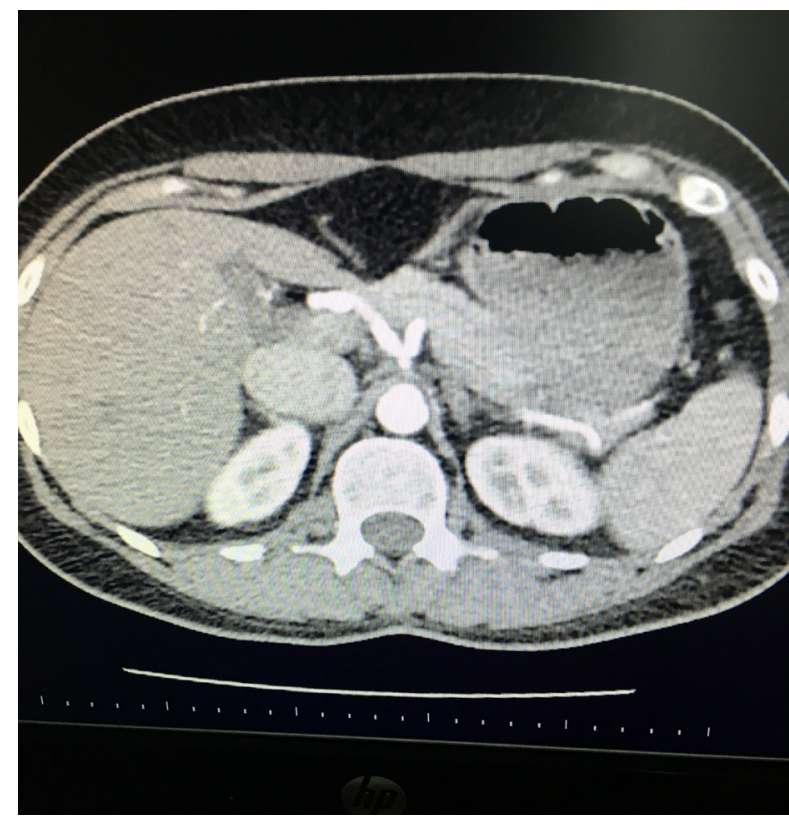

Şekil 1. Lezyonun bilgisayarlı tomografi anjiografi görüntüsü

sigara kullanımı ve ailede periferik arter hastalığı (PAH) öyküsü vardı. CT anjiografi raporunda, ÇA orijin düzeyinde kan akımı olmadığı, ÇA doluşunun SMA proksimalinden orijin alan kollateraller yoluyla sağlandığı ve SMA proksimal kesimde \%50 darlık olduğu belirtildi. (Şekil 1 ve 2) Ayrıca sağ arterya dorsalis pedisin oblitere olduğu raporlandı. Girişimsel işlem için radyoloji kliniği ile konsulte edildi. Ancak

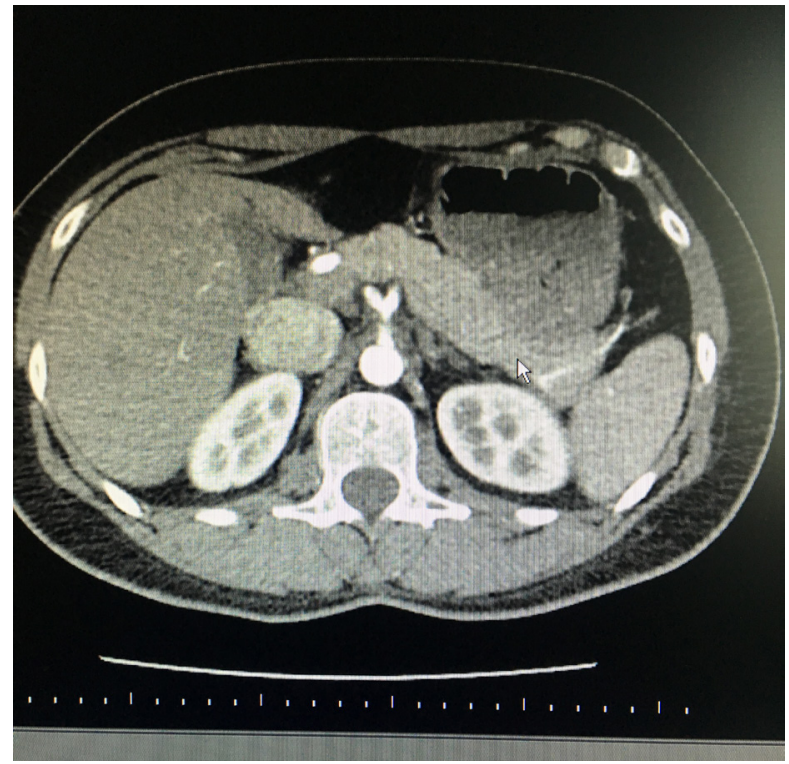

Şekil 2. Lezyonun bir başka açıdan görüntüsü

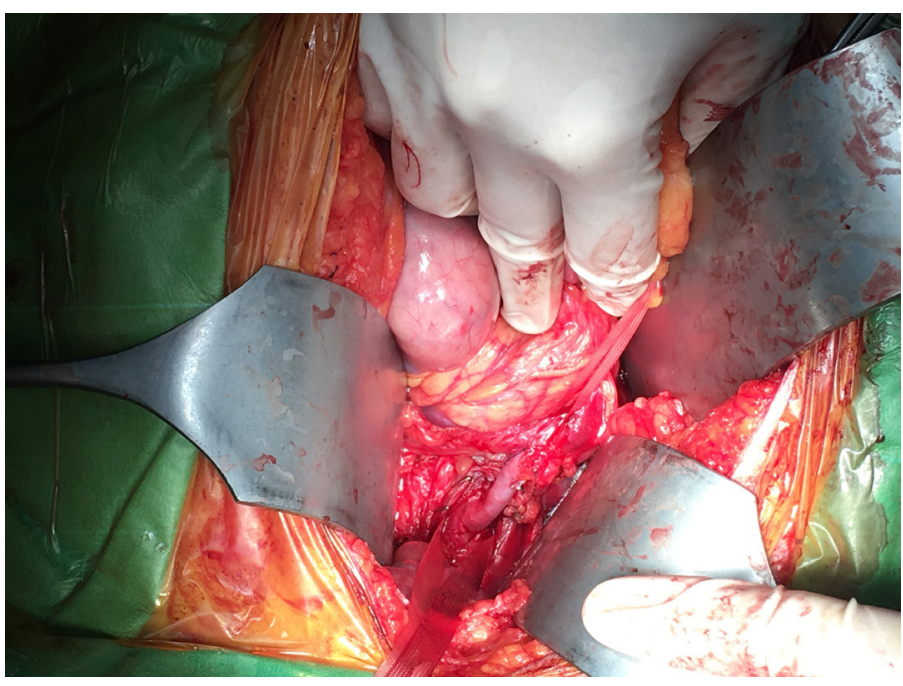

Şekil 3. Supraçölyak aorta ile common hepatik arter arasına safen ven interpozisyonu

birden fazla lezyon olması ve ÇA dallarında da hastalığın devam etmesi nedenleriyle girişimsel işleme uygun olmadığı kararı verildi. Hasta elektif şartlarda cerrahiye alındı. Üst orta hat batın vertikal insizyonu yapıldı. Supraçölyak aorta ile common hepatik arter arasına yaklaşık $3 \mathrm{~cm}$ uzunluğunda safen ven greft interpozisyonu gerçekleştirildi. (Şekil 3) Common hepatik arter, ulaşımı daha kolay olması ve lezyon bulunmaması nedeniyle distal anastomoz yeri olarak kullanıldı. Klinik takiplerinde problemi olmayan hasta postoperatif 4. gün taburcu edildi. Bir hafta ve bir ay sonra yapılan kontrol muayenelerinde hastanın şikâyetlerinin düzeldiği görüldü.

\section{TARTIŞMA}

İzole ÇA stenozu görülme oranlarının, otopsi serilerinde \%24'e kadar ulaştığı belirtilmektedir (1). Gastrointestinal sistemin birinci bölümü ÇA tarafından, orta kısmı SMA ve son bölümü ise inferior mezenterik arter tarafından beslenir. Kronik iskemide kollateral dolaşım iyi geliştiği için semptomlar çoğu zaman bu üç arterden en az ikisinde lezyon olduğunda ortaya çıkmaktadır (2). Kronik mezenterik iskemide meydana gelen yemek sonrası karın ağrısının nedeni, bağırsakların, toklukta sindirimi sağlayabilmek amacıyla daha fazla oksijene intiyaç duymasıdır. Yemeklerden sonra oluşan ağrı nedeniyle hastalar yemek yemekten kaçınır hale gelir. Bu sürecin uzaması durumunda doğal olarak kilo kaybı meydana gelir. PAH tanısı konan hastaların \%16,1'inde ÇA, $\% 13$ 'ünde renal arter, \%8,6'sında ÇA ve renal arter, 
\%5,3'ünde ÇA ve SMA tutulumları olduğu bildirilmiştir (3). Olgu sunumu yapılan hastada aterosikleroz risk faktörlerinden aile öyküsü ve sigara içimi bulunuyordu. Aterosikleroz semptomlarının genellikle ileri yaşlarda ortaya çıktığı düşünülürse bu hasta için 35 yaşında PAH varlığı, ÇA ve SMA tutulumu olması nadir görülmesi açısından önemlidir. Genç yaşta tıkayıcı arter hastalığı yapabilecek nedenler arasında behçet hastalığı, sifiliz, madde bağımlılığı, takayasu arteriti ve atrial fibrilasyon da bulunmaktadır. Hastanın anamnezi ve tetkiklerinde bu hastalıklara ait bulguya rastlanılmadı. Ayrıca EKO'sunda venöz kaynaklı (protein c, protein $\mathrm{s}$, antitrombin III eksikliği, faktör $\mathrm{V}$ leiden mutasyonu $\mathrm{vb}$ ) nedenlerden, paradoksal emboliye sebep olabilecek patent foramen ovale izlenmedi.

Endovasküler girişimler son yıllarda tecrübenin de artmasıyla birlikte hastanede kalış süresinin kısalması, daha az invaziv olması ve komplikasyon oranlarının cerrahiye göre daha düşük seyretmesi gibi avantajlar içerir. Klasik cerrahi yapılması önerilen vakalar ise birden fazla damarda lezyon varlığı, işlem için uygun olmayan lokalizasyonlar ve uzun lezyonlar olması, bağırsak nekrozu bulunması, akut ligaman kompresyon darlığı dışındaki basıya bağı darlık vakaları olarak belirtilmiştir (4). Bu hastada çölyak arter ostealinden başlayan uzun lezyon varlığı ve birden fazla lokalizasyonda hastalığın bulunması endovasküler girişim yerine cerrahi tedaviyi ön plana çıkarmıştır. Cerrahi tedavi yöntemlerinden endarterektomi, erken dönem başarısı \%93, üç yıllık dönemde sağ kalım \%77-\%85 oranlarıyla uygun hastalar için iyi bir alternatiftir (5). Cerrahide diğer alternatif olan bypass, torasik veya supraçölyak aorttan antegrad ya da infrarenal aort veya iliyak arterlerden retrograd olarak yapılabilmektedir. Safen ven grefti kullanımı sonuçları başarılı bulunmuştur. Beş yıllık greft açıklığı \%78 ve antegrad bypass seçeneğinin uzun dönemde mortalite-morbidite açısından daha sorunsuz olduğu raporlanmıştır (6). Üç yıl sonunda tekrarlayan semptom görülme oranı anjioplasti grubunda anlamlı derecede fazla bulunmuştur (7). Cerrahi tedavinin uzun dönem sonuçlarının daha iyi olduğu ve ikincil girişimlerin daha az gerektiği raporlanmıştır (8).

Endovasküler yöntemlerin başarılı olduğunu vurgulayan çalışmalarda mevcuttur. Erken-orta dönem endovasküler işlem sonuçlarının açıklandığı bir çalışmada, düşük komplikasyon ve yüksek sağ kalım oranları bildirilmektedir (9). Bir başka çalışmada lezyon bölgesine önce balon yapılıp ardından stent yerleştirilerek başarılı sonuç alındığı belirtilmiştir (10). Ülkemiz için endovasküler işlemlerde maliyet yüksekliği sorunu hala devam etmektedir. Arteryel greftlerin venöz greftlere üstünlüğü bilinmektedir. $\mathrm{Bu}$ hasta gibi genç vakalar için arteryel greft kullanımı düşünülebilirdi. Ancak safen ven kullanımı sonuçlarının iyi olması, arteryel greft kullanımı ile ilgili yeterli çalışma ve sonuçların bulunmaması ayrıca çap uygunsuzluğu olabileceği endişesi ile safen ven kullanıldı. Kronik mezenterik iskemili hastaların \%26-66'sı tedavi edilmediği takdirde akut iskemi ve bağırsak infarktüsü ile karşılaşabilmektedir (11).

Sonuç olarak karın ağrısı olan hastalarda kronik mezenterik iskemi olabileceği de akılda tutulmalıdır. Asemptomatik hastalar, ilerde bağırsak infarktüsü ile karşılaşılmaması için takip edilmelidir. Tedavide endovasküler girişim için uygun olmayan vakalarda cerrahi yöntemler iyi bir alternatiftir.

Çıkar Çatışması: Çalışmada herhangi bir çıkar çatışması yoktur.

Finansal Çıkar Çatışması: Çalışmada herhangi bir finansal çıkar çatışması yoktur.

Yazışma Adresi: Mehmet Işık, Necmettin Erbakan Üniversitesi, Meram Tıp Fakültesi, Kalp ve Damar Cerrahisi Anabilim Dalı Konya, Türkiye

Tel: 5335507549

E-mail:drmisik@hotmail.com

\section{KAYNAKLAR}

1. Park CM, et al. Celiac axis stenosis: Incidence and etiologies in asymptomatic individuals. Korean J Rad 2001;2:8-13.

2. Pietura R, Szymanska A, El Furah M, et al. Chronic mesenteric ischemia: Diagnosis and treatment with balloon angioplasty and stenting. Med Sci Monit 2002;8:PR8-PR12.

3. Widman A, Speranzini $M B$, de Oliveira $I R$, et al. Atherosclerotic stenosis of the main branches of abdominal aorta. (Prevalence in patients with lower limb occlusive vascular disease) Arq Gastroenterol 1998;35:18-25.

4. Landis MS, Rajan DK, Simons ME, et al. Percutaneous management of chronic mesenteric ischemia: Outcomes after intervention. J Vasc Interv Radiol 2005;16:1319-25.

5. Lau H, Chew DK, Whittemore AD, et al. Transaortic endarterectomy for primary mesenteric revascularization. Vasc Endovascular Surg 2002;36:335-41.

6. Moawad J, McKinsey JF, Wyble CW, et al. Current results of surgical therapy for chronic mesenteric ischemia. Arch Surg 1997;132:613-8.

7. Biebl M, Oldenburg WA, Paz-Fumagalli R, et al. Surgical and interventional visceral revascularization for the treatment of chronic mesenteric ischemia when to prefer which? World $\mathrm{J}$ Surg 2007;31:562-8.

8. Kolkman JJ, Mensink PB, van Petersen AS, et al. Clinical approach to chronic gastrointestinal ischaemia: From 'intestinal angina' to the spectrum of chronic splanchnic disease. Scand J Gastroenterol Suppl 2004;241:9-16.

9. Dias NV, Acosta S, Resch T, et al. Mid-term outcome of 
endovascular revascularization for chronic mesenteric ischaemia. Br J Surg 2010;97(2):195-201

10. Kılıçgedik A, Kırma C, İzgi İA. Stent implantation of critical stenosis in celiac trunk. Koşuyolu Heart Journal 2015;18(2):107.
11. Thomas $\mathrm{JH}$, Blake $\mathrm{K}$, Pierce GE, et al. The clinical course of asymptomatic mesenteric arterial stenosis. J Vasc Surg 1998;27:840-4. 